\title{
AN ECO-APPROACH TO MODULARITY IN URBAN LIVING
}

\author{
ÁGNES BORSOS ${ }^{1}$, JENO BALOGH $^{2}$, BALÁZS KOKAS $^{1}$ \& BÁLINT BACHMANN ${ }^{1}$ \\ ${ }^{1}$ University of Pécs, Hungary, EU. \\ ${ }^{2}$ Metropolitan State University of Denver, Colorado, USA.
}

\begin{abstract}
Today, half of the world's population lives in cities, which could reach $75 \%$ by 2050 . Expanding urban areas will increasingly impact the already strained natural habitats, thus, economically and ecologically advantageous housing solutions are needed. This paper presents the research on a sustainable urban residential building concept that addresses this need. To ensure affordability, prefabrication and mass production were adopted, resulting in a unique, non-monotonous structural concept that is adaptable to different living unit sizes and layouts. A modular system was developed consisting of a basic living unit, which defines interior spaces, furniture, and structures. The modules can be placed next to each other to satisfy the needs of people for various living spaces. By carefully choosing a module size, enough combinations can be created, and individual solutions can be prefabricated. This system can also be produced in a large-scale that too in an eco-friendly way by utilizing novel building materials. Cross-laminated timber and timber-concrete composites were found to be the ideal choices for the walls and the slabs, respectively, as both are easily prefabricated, thereby decreasing the ecological footprint of the project. In addition, the building's vertical size is efficiently maximized to seven living levels, while still keeping it human-scale in an urban setting. This new modularity, as described, provides a sustainable answer to the challenge of expanding urban living.

Keywords: Eco-friendly building, Modularity, Prefabrication, Urban living.
\end{abstract}

\section{INTRODUCTION}

With the world's population increasingly living in cities, municipalities risk by rapidly outgrowing their boundaries and infrastructure thus, impacting the natural habitats and the affordability of urban living. Therefore, an eco-approach to sustainable urban living such as the one described in this paper is needed.

This study presents a solution that uniquely uses a composite construction material (CLTconcrete), suitable for advanced manufacturing (prefabrication) in conjunction with variable modular living units, to create a building that addresses the issues described above.

In the 1960s across Europe, in Central and South America, buildings constructed with Soviet technology allowed for a rapid urbanization process, and in many cases they have defined the image of the cities. For example, in Germany, some intriguing examples are: Sachsendorf-Madlow in Cottbusm or Märkisches Viertel and Hellersdorf in Berlin. These show how refurbishment should be performed and reveal how one might build for/in the future. In terms of evaluating the quality of these structures, there are structural and financial aspects that define the fate of these buildings that sociologists, psychologists, and architects have been tackling for almost three decades. Incomplete solutions were often created, while full rehabilitation could rarely be seen. Subsequently, there have been several proposed solutions to creating variable living units, one example being the Diagoon House, Delft (1971) which was designed by Hermann Hetzberg with the concept to create the 'incomplete building' where residents formed their own spaces in accordance with their needs, as well as keeping the relationship between rooms open [1]. Nevertheless, the construction materials used in these prior attempts (usually reinforced-concrete, steel, or timber) impose limits on the architectural design that are avoided in the solution described herein. 


\section{CONCEPT}

The eco-approach to modular urban living presented in this paper uniquely combines sustainable/composite structural members that allow for prefabrication/mass production, with variable modularity through the architectural design.

\subsection{Modular variations}

In modern architecture, uniqueness has to be provided for the denizens of a residential building to match the diverse needs of different people [2]. In order to develop a variable living space design, it is highly important that its topological characteristics be easily changeable and therefore customizable. Living spaces do not only serve to satisfy human needs, they also seek to bring comfort to its inhabitants by the increasing quality of living experiences. Therefore, the authors define the variable living units as the ones that can adapt to the changing needs of the users, by incorporating the choice of different living space layouts prior to taking possession, as well as the ability to reconfigure it over time [3].

The key to modular architectural design is its ability to provide for a large number of variations. Music could be an example for such modularity. With the eight basic musical notes and their combinations, it is possible to create simple melodies or the most complex music as well. In the case of music, eight notes (modules) are enough to create endless variants. How many basic modules are enough to create endless variety in architecture? In music, with the proper choice of module size, a great variety could be reached. The goal of the research is to find an affordable, quick to build, quality solution for future housing, while also bearing in mind the uniqueness frequently sought nowadays.

In construction, modularity can affect the functional and structural system of a building. The structural solution has an important effect on the spatial variety and the spatial modularity. Since the 19th century several structural module systems have been worked out. To get an adequate system of modular coordination, the International Standards Organization set the basic module at $10 \mathrm{~cm}$, which, later, was adopted by the great majority of European countries. However, in current practice, architects use base module sizes of $120 \mathrm{~cm}$ leading to a series of $60,120,240,360,480,600,720 \mathrm{~cm} \mathrm{[4].}$

Several classical solution examples could be found for modular buildings, in which modularity defines the structure. Plattenbau provides an example with a module size of 2.70 $\mathrm{m} / 3.60 \mathrm{~m}$ transversely and $5.40 \mathrm{~m}$ in length. The structural constraints present in this type of modularity result in fragmented living spaces. In addition, the fixed transverse structural dimension limits the space variations [5].

In contrast to the classical solution, there are fewer solution examples in which the modularity originates from the usage of space. In this research, the modules were derived from the usage of the interior spaces in order to achieve the right spatial variety. The modular elements have to solve the user's individual space needs, with optimal modular combinations. A $30 \mathrm{~cm}$ $\times 30 \mathrm{~cm}$ minimum module was selected for the modular grid of the building, see Fig. 1 . The basic elements that the concept defines are space dividing elements, and furniture. The system of modules created was introduced with the basic units for the minimum necessary amount of space derived from ergonomics of use. The $60 \mathrm{~cm}$ unit (shoulder width), widely used in the furniture industry, and the $90 \mathrm{~cm}$ unit in the circulation areas are the bases of the modular system. The $30 \mathrm{~cm} \times 30 \mathrm{~cm}$ module size provides the adequate number of combinations within the network. According to the concept, furniture serves as space dividers and creates living spaces. 


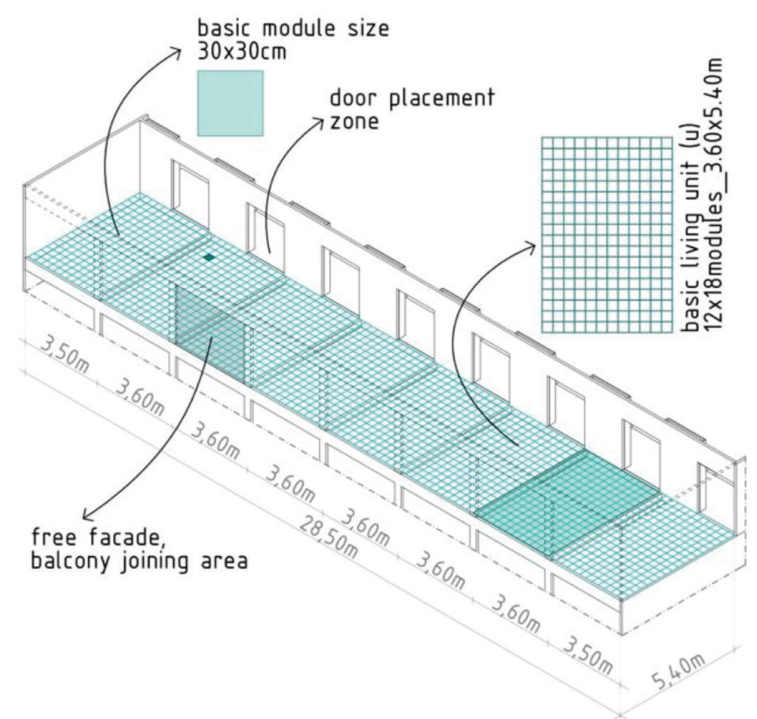

Figure 1: The module system and the basic units of the concept.

In line with the $30 \mathrm{~cm} \times 30 \mathrm{~cm}$ grid system, a modular furniture collection (toolbar) was designed in accordance with the corresponding world standards, which can accommodate different configurations to fulfill the needs of the users. The toolbar element combinations, the spatial configurations, and the relationship with other toolbar elements provide the needed spatial topology. In order to use the modules in the most efficient way and get the most variety, a flexible construction method was needed.

\subsection{Structural materials}

The factors considered in selecting the materials of the modular structural system besides the sustainability, environmental impact, and affordability were the ability for prefabrication and mass production by advanced manufacturing. In this study, CLT-concrete composite floor slabs are uniquely used in conjunction with a variable living unit-based modular building. These composite floors combine the sustainability of the CLT with the strength, stiffness, and fire resistance of the concrete material. The use of CLT panels in buildings is seeing rapid growth $[6,7,8]$. The advanced manufacturing uses CAD generated data to drive CNC processes, which makes it an ideal choice for a prefabricated and modular building.

In a composite laminated timber-concrete (LTC) $[9,10,11]$ slab the CLT layer is interconnected with a concrete layer on the top. A continuous and rigid inter-layer connection is achieved with the use of a high moisture-tolerant epoxy-based adhesive. The adhesive layer is applied on the CLT layer immediately before the fresh concrete is placed over the top. For the load-bearing walls, regular CLT panels are used.

\subsection{Prefabrication and mass production}

Prefabrication and modularization can be good alternatives in building construction in the future decades. There are several factors that should be taken into consideration when 
comparing prefabrication with the traditional on-site construction methods. The environmental benefits of prefabrication are considerable. The waste production of construction can be reduced by using industrialized techniques. Begum et al. showed in their study that the amount of waste generated by weight was 1.47 tons $/ 100 \mathrm{~m}^{2}$ floor space for a fully prefabricated building, while it was 54.64 tons for a conventional type. The recycling percentage was also better for prefabrication [12]. Tam et al. in 2007 and Li et al in 2014 [13,14] found similar results. Building time and labor needs can also be significantly reduced with off-site construction methods, according to Boafo et al. (2016) [15].

Building costs of prefabricated construction, however, could be higher than that incurred by traditional methods. Mao et al. (2016) showed in their study that the usage of prefabricated elements causes a significant increase in the total cost of a building [16]. However, this increase comes mainly from the manufacturing of the prefabricated elements, transportation, and design consultancy. The technology is relatively new and there is little experience in the market. In the coming decades, considering the environmental benefits, this fact could change, and, therefore, these costs could be reduced. It has to be mentioned that the higher costs can be compensated with time and labor savings as mentioned earlier as well as by the use of advanced manufacturing.

\section{RESULTS}

The concepts presented in this paper were applied to a residential building in an urban setting, see Fig. 2.

A frame structural solution was adopted due to its fitness for modularity and for living space variability. This ensures that the residential area is free of load-bearing elements while the loads are supported by the façade pillars and the walls parallel to the circulation area. The habitable zone appears as a rectangular space in the building, and its size is defined by the size of modules. By multiplying the $30 \mathrm{~cm} \times 30 \mathrm{~cm}$ basic modules, a basic living space unit is created, which consists of $18 \times 12$ basic modules, namely $5.40 \mathrm{~m} \times 3.60 \mathrm{~m}$. The actual residential living units were created by multiplying the living space units, which are based on the number of residents and living conditions, and are as follows, see Fig. 1.: single resident two units $\left(\sim 38 \mathrm{~m}^{2}\right)$, couples and families with children three units $\left(\sim 58 \mathrm{~m}^{2}\right)$, families with several children four units $\left(\sim 78 \mathrm{~m}^{2}\right)$ should be ideal and would still produce a comfortable living space.

The length of the residential zone was maximized by placing eight living space units in the longitudinal direction, which means approximately $30 \mathrm{~m}$ along the length of the building. It forms a human-scale building block in the urban environment, which can provide for the needed number of variations. Living units can be placed in six different ways on one floor, not including the mirrored versions, see Fig. 3. The vertical size of the building was defined

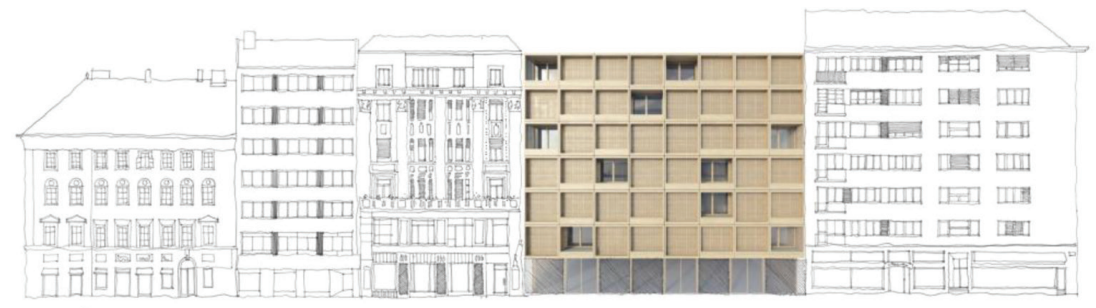

Figure 2: Possible street view of the designed building in an urban setting. 


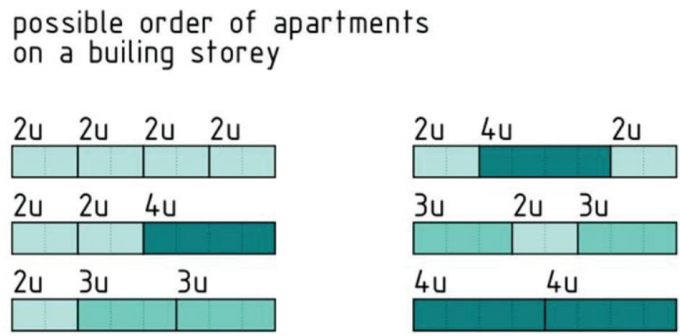

Figure 3: Possible placement of living units in the building.

as seven floors for similar reasons. A horizontal area and a vertical circulation area, as well as community spaces, are connected to the residential zone.

The $5.40 \mathrm{~m}$ span forms the depth of the tract, which is also suitable as far as natural light is concerned. The consideration of natural light when creating living spaces is of crucial importance, from both a mental health perspective as well as an energy-conscious decision [17].

Plumbing zones and other restricting factors are problematic in establishing the freedom of the floorplan and transparency. In order to place the appliances in a rational way, plumbing zones were formed within the living units and were connected to the main pipeline in the direction of the corridors. The horizontal pipelines join the vertical riser connecting the plumbing zones above, which also provides space for the appliances belonging to each living unit, as shown in Fig. 4.

When the concept is applied to a residential building with seven floors, the living zone is the central unit as shown in Fig. 5. This unit is completed by a public/commercial function on the ground level, and the zones are connected with a vertical and a horizontal walkway system. The combination of the zones can be adapted to various urban environments, see Fig. 5 .

The steel structure of the façade contains balcony units to complete the comfortable residential areas and to enhance the natural connection of the living units. Due to the free floor layout and natural illumination, a pillar structural solution made of steel complements the concept here. The steel structure of the façade is connected to the longitudinal main wall (5.40 m span) with steel beams. These steel beams, placed $3.60 \mathrm{~m}$ on-center, support the LTC

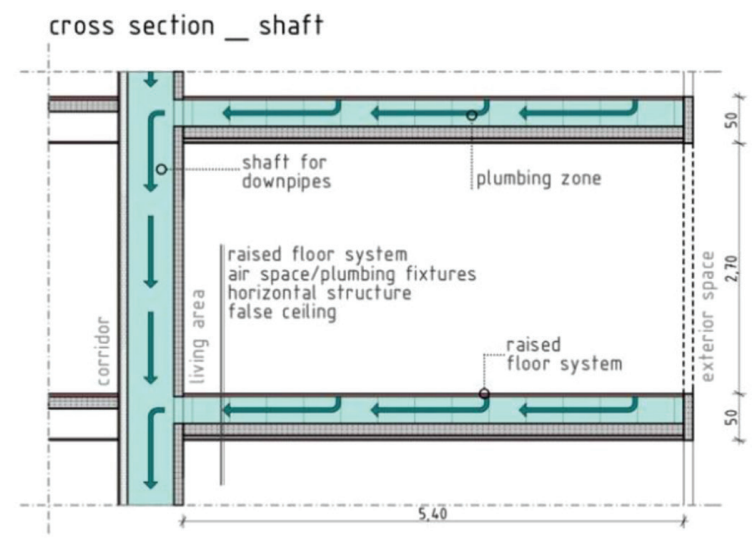

Figure 4: Solution of the plumbing zones. 


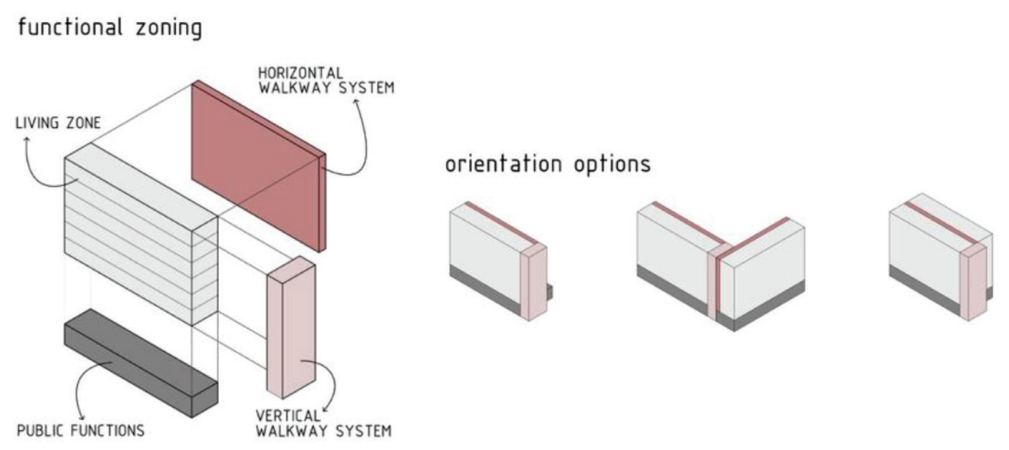

Figure 5: Functional zoning of the building with orientation options.

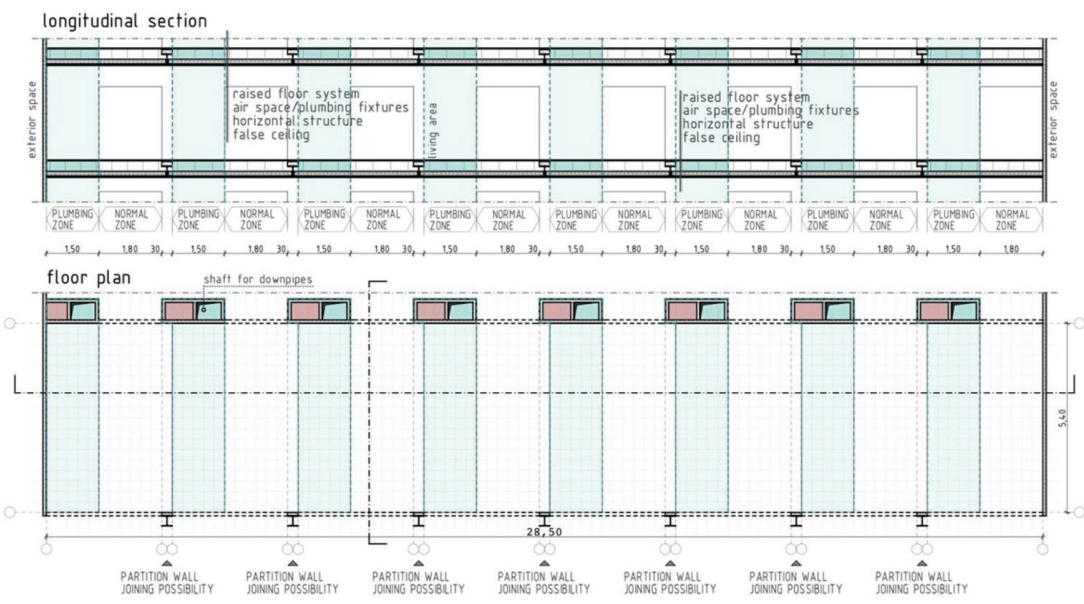

Figure 6: Structural system of the building.

slab above which the utilities can be found underneath a raised floor, without penetrating the structure of the slab, as shown in Fig. 6.

\section{CONCLUSIONS}

This paper presents an eco-approach to the use of modularity and sustainable modern structural materials to create variable living units. Every action affects the future, and this is not only important in terms of selecting the proper building materials, but it is also important in terms of creating sustainable living spaces.

The adoption of a $30 \mathrm{~cm} \times 30 \mathrm{~cm}$ space-driven basic module size allows for a large number of modular variations. Thus, the living units and the structural system provide for adaptability and suitability for changing needs and environments over time. As a result, during its lifecycle, the building will be able to serve residential needs for several generations.

The modularity provided by the adopted living space unit size of $3.6 \mathrm{~m} \times 5.4 \mathrm{~m}$ allows for prefabrication, and in conjunction with the use of CLT in walls and slabs, allows for mass production by means of advanced manufacturing. 
The CLT-concrete composite slabs ensure higher strength and stiffness [9] as well as greater fire resistance than the CLT slabs and a lighter structure when compared to reinforced concrete slabs.

In addition to the use of sustainable CLT and CLT-concrete composite materials which decrease the ecological footprint of the structure, the energy performance analysis results [11] indicate the adequacy of such buildings for geothermal or hot water heating systems.

\section{REFERENCES}

[1] AHH Office Website, Diagoon experimental housing, Delft, from: https://ahh.nl/index. php/en/projects2/14-woningbouw/79-diagoon-experimental-housing, 2018.

[2] Smith, R.E. \& Timberlake, J., Prefab Architecture: A Guide to Modular Design and Construction. New Jersey, USA: Wiley, 2011.

[3] Till, J. \& Schneider, T., Flexible housing: The means to the end. Architectural Research Quarterly, 9(3-4), 287, 2005. https://doi.org/10.1017/s1359135505000345

[4] Fraunhofer IRB Website, H. Schmidt - modular coordination, repetition and architecture, from http://irbnet.de/daten/iconda/CIB15237.pdf

[5] Ambró, P., Balázsi, I., Békés, M. \& Csöndes, A., A panelos lakóépületek felújítása. Budapest, M szaki Könyvkiadó, 1993.

[6] Build Up Website, Treet - A wooden high-rise building with excellent energy performance, 2018 from http://buildup.eu/en/practices/cases/treet-wooden-high-risebuilding-excellent-energy-performance

[7] Professner, H. \& Mathis, C., LifeCycle tower-high-rise buildings in timber. ASCE Structures Congress, 2012, 1980-1990. Chicago, USA.

https://doi.org/10.1061/9780784412367.174

[8] Offsite Hub Website, Banyan wharf - by B\&K structures, from https://offsitehub.co.uk/ projects/banyan-wharf-by-xlam-alliance, 2018.

[9] Balogh, J., Laminated wood-concrete structural members. Pollack Periodica, An International Journal for Engineering and Information Sciences, 8(3), 79-86, 2013. https://doi.org/10.1556/pollack.8.2013.3.8

[10] Szucs, I., Balogh, J. \& Holtzman, R., Acoustic emission investigation of laminated timberconcrete test beams. International Journal of Computational Methods and Experimental Measurements, 5(6), 884-93. 2017. https://doi.org/10.2495/cmem-v5-n6-884-893

[11] Kistelegdi, I., Balogh, J., Bachmann, B. \& Baranyai, B., Potential Analysis of the Energy And Climate Performance of Wood-Concrete Hybrid Building Structures, Proceedings of the World Conference in Timber Engineering, WCTE-2014, Quebec City, CA, 2014.

[12] Begum, R.A., Satari, S.K. \& Pereira, J.J., Waste generation and recycling: comparison of conventional and industrialized building systems. American Journal of Environmental Sciences, 6(4), 383-88, 2010. https://doi.org/10.3844/ajessp.2010.383.388

[13] Tam, V.W., Tam, C.M., Zeng, S.X. \& Ng, W.C., Towards adoption of prefabrication in construction. Journal of Building and Environment, 42(10), 3642-54, 2007. https://doi.org/10.1016/j.buildenv.2006.10.003

[14] Li, Z., Shen, G.Q. \& Alshawi, M., Measuring the impact of prefabrication on construction waste reduction: An empirical study in China. Resources, Conservation and Recycling, 91, 27-39, 2014. https://doi.org/10.1016/j.resconrec.2014.07.013

[15] Boafo, F.E., Kim. J.H. \& Kim, J.T., Performance of modular prefabricated architecture: case study-based review and future pathways. Sustainability, 8(6), 558, 2016.

https://doi.org/10.3390/su8060558 
[16] Mao, C., Xie, F., Hou, L., Wu, P., Wang, J. \& Wang, X., Cost analysis for sustainable off-site construction based on a multiple case study in china. Habitat International, 57, 215-22, 2016. https://doi.org/10.1016/j.habitatint.2016.08.002

[17] Hausladen, G., De Saldanha, M., Liedl, P. \& Sager, C., Climate Design. Basel, Switzerland: Birkhauser, 2005. 